\title{
Characteristics and outcomes of foreign body ingestion in children
}

\author{
Gerardo Blanco-Rodríguez, M.D. ${ }^{a}$, Gustavo Teyssier-Morales, M.D. ${ }^{a}$, \\ Jaime Penchyna-Grub, M.D. ', Jorge E. Madriñan-Rivas, M.D., \\ Iván A. Rivas-Rivera, M.D. ${ }^{a}$, Adrián Trujillo-Ponce de León, M.D. ${ }^{a}$, \\ Juan Domingo-Porras, M.D. ${ }^{a}$, José G. Jaramillo-Alvarado, M.D. ${ }^{a}$, \\ Ebenezer V. Cruz-Romero, M.D. ${ }^{a}$ and Jessie N. Zurita-Cruz, M.D. ${ }^{b}$
}

\begin{abstract}
Introduction: Foreign body (FB) ingestion is a common home accident during childhood; a timely management by the specialists may help prevent complications in the short and long term. Objective: To describe the characteristics and complications of FB ingestion located in the gastrointestinal tract in the pediatric population. Material and methods: Two phases, retrospective, and prospective study. Patients diagnosed with FB ingestion between January 1971 and December 2016 were included. The general characteristics of patients, FB type, removal method, and complications were registered. A descriptive analysis was performed.

Results: Over 45 years, 2637 FBs were removed from the pharynx $(n=118)$, the esophagus $(\mathrm{n}=2410)$, the stomach $(\mathrm{n}=103)$, and the intestines $(\mathrm{n}=6)$. Male patients predominated $(50.9 \%) ; 74 \%$ were younger than 5 years. Besides, $57 \%$ arrived within the first 24 hours; ptyalism, dysphagia, and vomiting were the main symptoms; $16 \%$ of patients had no symptoms. It was possible to locate the FB using an X-ray in $93 \%$ of cases; the most common FBs were coins $(78 \%)$; the most frequent location was the upper third of the esophagus (79\%); $86 \%$ of FBs were removed using a rigid endoscope, and complications were observed in $7.8 \%$ of patients.

Conclusions: FB ingestion predominated among children younger than 5 years; metal objects were the most common ones. A plain X-ray is the test of choice for diagnosis; removal is usually done with a rigid or flexible endoscope, depending on the endoscopist's experience.

Key words: foreign bodies, complications, pediatrics.
\end{abstract}

http: / / dx.doi.org/10.5546/aap.2018.eng.256

To cite: Blanco-Rodríguez G, Teyssier-Morales G, Penchyna-Grub J, et al. Characteristics and outcomes of foreign body ingestion in children. Arch Argent Pediatr 2018;116(4):256-261.

\section{INTRODUCTION}

Foreign body (FB) ingestion is a common home accident during childhood. In the United States of America, in 2014, the American Association of Poison Control Centers reported that more than 128000 patients had ingested a FB; of these, more than $69 \%$ were children younger than 5 years and $83 \%$, children and adolescents younger than 19 years. ${ }^{1}$ Pediatric patients, mainly infants, toddlers, and preschoolers, are at a higher risk for FB ingestion. This has been related to the combination of curiosity typical of the development of infants, toddlers, and preschoolers, their tendency to put everything in the mouth, swallowing coordination difficulties due to immaturity, and the absence of molars and premolars. ${ }^{2}$

The natural history of FB ingestion refers that between $80 \%$ and $90 \%$ of FBs will spontaneously pass through the gastrointestinal tract and get expelled through the rectum; only $10-20 \%$ will be retained and require endoscopic removal, and less than $1 \%$ will require surgical removal. ${ }^{3}$ The initial diagnosis is based on a high degree of suspicion together with the history referred by the parents of a sudden-onset condition or the history of seeing the child putting an item in his / her mouth while playing or the history referred by the patient him/ herself, followed by symptom onset.

Although several publications have described the epidemiology of FB ingestion, diagnosis, and management, to date there is controversy regarding certain aspects, such as the adequate time for an endoscopy in a patient with 
a history of FB ingestion if there are no symptoms or whether or not doing a baseline X-ray to define the diagnosis and management of these patients. ${ }^{2-7}$ The complications of FB ingestion may vary from edema, erosion, and perforation to death in very rare cases.

The objective of this study was to describe the characteristics of patients, FBs, removal method, and the complications observed over 45 years of experience in a tertiary care children's hospital.

\section{MATERIAL AND METHODS}

A retrospective, prospective study was conducted in patients diagnosed with FB ingestion who were admitted to the Department of Chest Surgery and Endoscopy of a tertiary care children's hospital.

During the retrospective phase of the study, we looked for the medical records of patients diagnosed with FB ingestion between January 1971 and December 2002. During the prospective phase, between January 2003 and December 2016, all patients who were admitted to the Emergency Department suspected of FB ingestion and who underwent an endoscopy or other type of procedure for FB removal were identified. Patients diagnosed with FB ingestion who had been seen at a different hospital were excluded, and incomplete medical records or those with missing data were left out.

During both study phases, patients' characteristics were identified, including age, sex, time elapsed since symptom onset or from the moment FB ingestion was detected until care was received, presence of a disease that may have favored FB retention, clinical presentation, FB nature, type, location, radiological findings, removal methods and instruments, and whether there was any complication.

\section{Statistical analysis}

A descriptive analysis of outcome measures was done using frequency and proportion. Data were analyzed using the STATA version 12.0 statistical software package.

\section{RESULTS \\ Characteristics of patients with foreign body ingestion}

Over the 45-year period, a total of 2803 FBs were removed from the gastrointestinal tract. Of these, 1494 were identified in the study's retrospective phase; 166 corresponded to incomplete medical records and were excluded, resulting in 1328 cases of FB ingestion. During the prospective phase, 1309 cases of FB ingestion were identified.

A total of 2637 patients with FB ingestion were included; of these, 1343 (50.9\%) were boys. Patients' age ranged from 6 months to 17 years old; $74 \%$ corresponded to children younger than 5 years, and a peak incidence $(55 \%)$ was observed among those younger than 3 years (Table 1). In relation to the time elapsed since ingestion, more than half of the patients $(n=1508$, $57.1 \%$ ) attended the Emergency Department in the first 24 hours, but the time of the event was unknown in 19 cases (Table 1). The main location of FBs was the esophagus $(n=2410)$, followed by the pharynx $(n=118)$, the stomach $(n=103)$, and the intestines $(n=6)$. Out of all patients, $73(2.7 \%)$ had a pre-existing condition. The main pre-existing condition was esophageal stenosis in 69 patients; in 24 of them, it was caused by caustic ingestion; in 20, by esophageal surgery;

TABLE 1. General characteristics of patients with foreign body ingestion

\begin{tabular}{|c|c|c|}
\hline Age & $\mathbf{n}$ & $(\%)$ \\
\hline $0-23$ months old & 551 & $(20.9)$ \\
\hline 2-3 years old & 897 & $(34.0)$ \\
\hline $4-5$ years old & 498 & $(18.9)$ \\
\hline 6-7 years old & 292 & $(11.1)$ \\
\hline 8-9 years old & 176 & $(6.7)$ \\
\hline 10-11 years old & 91 & $(3.5)$ \\
\hline$>12$ years old & 132 & $(5.0)$ \\
\hline \multicolumn{3}{|l|}{ Time elapsed since ingestion } \\
\hline 24 hours & 1508 & $(57.2)$ \\
\hline 1-2 days & 580 & $(22.0)$ \\
\hline 3-6 days & 370 & $(14.0)$ \\
\hline 7-29 days & 124 & $(4.7)$ \\
\hline$>30$ days & 36 & $(1.4)$ \\
\hline Unknown & 19 & $(0.7)$ \\
\hline \multicolumn{3}{|l|}{ Symptoms } \\
\hline Ptyalism & 1086 & $(41.2)$ \\
\hline Dysphagia/odynophagia & 826 & $(31.3)$ \\
\hline Vomiting & 815 & $(30.9)$ \\
\hline Pain & 348 & $(13.2)$ \\
\hline Nausea & 261 & $(9.9)$ \\
\hline Cough & 190 & $(7.2)$ \\
\hline Dyspnea & 156 & $(5.9)$ \\
\hline Others & 284 & $(10.8)$ \\
\hline No symptoms & 752 & $(28.5)$ \\
\hline \multicolumn{3}{|l|}{ Complications } \\
\hline Ulceration/laceration & 87 & $(42.2)$ \\
\hline Erosion & 84 & $(40.8)$ \\
\hline Burn wound & 20 & $(9.7)$ \\
\hline Deep ulceration & 7 & $(3.4)$ \\
\hline Perforation & 4 & $(1.9)$ \\
\hline Mediastinitis & 2 & $(1.0)$ \\
\hline Retropharyngeal abscess & 1 & $(0.5)$ \\
\hline Death & 1 & $(0.5)$ \\
\hline
\end{tabular}


and in 25, by other causes (congenital disease, gastroesophageal reflux, eosinophilic esophagitis, scleroderma, achalasia, tight fundoplication); besides, 4 patients had psychomotor impairment.

\section{Clinical and radiological diagnosis}

In relation to the clinical presentation, it is worth mentioning that patients may have had more than one sign or symptom. Ptyalism stood out and was observed in 1086 cases; 752 patients had no symptoms (Table 1).

The plain X-ray helped to locate radiopaque FBs in 2444 cases (93\%). However, the level of agreement was lower when the FB was located in the pharynx $(27.9 \%)$ and the middle and lower third of the esophagus $(66.9 \%$ and $67.03 \%)$ because FBs corresponded to foods like spinach or seeds (radiolucent FB); whereas a better agreement was observed when the FB was located in the upper third of the esophagus $(99.5 \%)$, the stomach $(99.02 \%)$, the duodenum and the small intestine $(100 \%)$, where almost all FBs were radiopaque (Table 2, Figure 1).

\section{Foreign body characteristics}

Regarding the nature of FBs, 2505 (95\%) were inorganic and 132, organic (5\%). In relation to their characteristics, $2354(89.3 \%)$ were blunt objects; 260 (9.8\%), pointed objects; and $23(0.9 \%)$, sharp objects. Among all FBs, the most common were coins in 2065 patients $(78.3 \%)$, pins and safety pins in $79(3 \%)$, jewelry in $78(3 \%)$, and chicken or fish bones in $75(2.8 \%)$, as shown in Table 3.

\section{Foreign body removal procedure}

FBs were removed using a rigid endoscope in 2259 patients, whereas a flexible endoscope was used only in 362 (Table 3). Nine FBs were pushed down to the stomach (and subsequently

TABLE 2. Number of foreign bodies identified with an X-ray compared to their actual anatomical location

\begin{tabular}{lcc}
\hline Location & X-ray & Actual \\
\hline Pharynx & 33 & 118 \\
Upper third of the esophagus & 2102 & 2110 \\
Middle third of the esophagus & 140 & 209 \\
Lower third of the esophagus & 61 & 91 \\
Stomach & 102 & 103 \\
Duodenum & 3 & 3 \\
Small intestine & 3 & 3 \\
\hline
\end{tabular}

evacuated); 7 patients required surgery: 1 in the esophagus (a penny that was absorbed into the mucosa, showing only its center, that could not be removed after several attempts); 2 in the stomach (a coin that, after 1 month, did not pass the pylorus and a hairpin that was lodged in the stomach for 17 days and, since there were no forceps for FBs back then [1982], the patient underwent a gastrostomy and removal of $\mathrm{FB}$ ); 1 in the duodenum (a $6-\mathrm{cm}$ nail that did not pass the angle of Treitz after 23 days of follow-up), and 3 in the intestines (a needle with signs of peritoneal irritation; a patient without symptoms and who did not show needle progression 3 days later, so he underwent a laparotomy and the needle was found in the abdomen covered by the omentum; and a patient who swallowed 17 magnets: 3 were removed from the pharynx, 8 , from the stomach, and 1 was lodged in the gastric wall, stuck to other magnets, which resulted in a gastrojejunal fistula that required repair).

\section{Complications}

A total of 205 complications $(7.8 \%)$ were reported, including lacerations in 87 patients, erosions in 84 , burn wounds in 20 , deep ulcerations in 7 , perforations in 4 , and mediastinitis, retropharyngeal abscess, and

FIGURE 1. Radiopaque and radiolucent foreign bodies

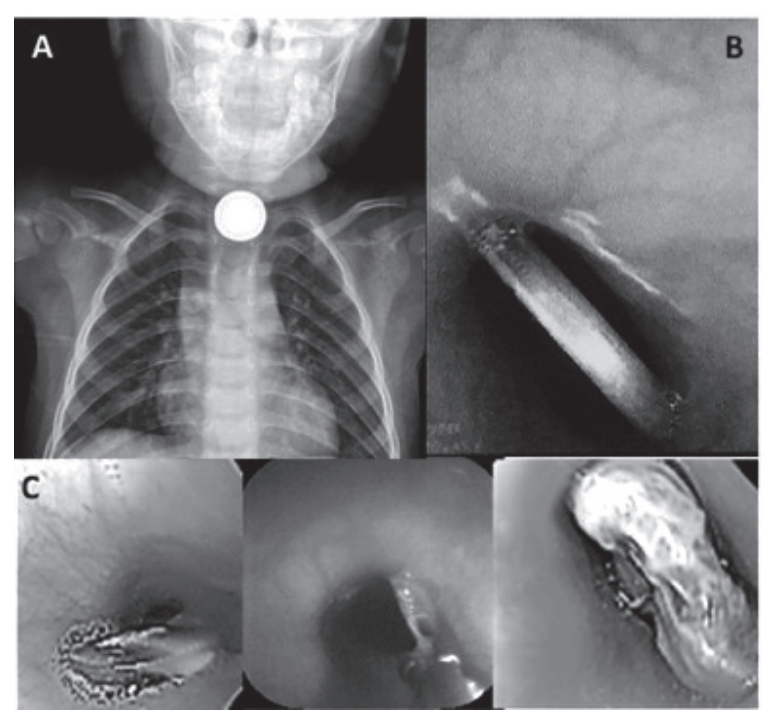

A. Plain X-ray of a radiopaque foreign body (coin) lodged in the cricopharyngeal sphincter.

B. Image showing the endoscopic removal of a coin.

C. Three radiolucent foreign bodies (glass, plastic, and food) that cannot be seen in a plain X-ray. 
death in 1 each. Among the patients who had a perforation, the FB was located in the esophagus in 3 of them (disc batteries) and the fourth patient had a gastrojejunal perforation (17 magnets). Mediastinitis occurred due to a perforation of the esophagus to the mediastinum caused by a FB whose nature was not described in the medical record; the patient required a pericardial window. The pharyngeal abscess was the result of child abuse: the patient had a 2-cm metal curtain hook inserted. The only death occurred in 1983, in a 9-year-old boy who arrived with hematemesis and hypovolemic shock and had an emergency exploratory laparotomy. During the procedure, it was observed that the bleeding came from the esophagus and, in view of suspected varices, a Sengstaken-Blakemore tube was inserted. Then, it was decided to perform a thoracotomy to ligate the esophageal varices and the coin came out while pulling out the tube. The patient had massive bleeding caused by an aortoesophageal fistula. During guided case history regarding the presence of a FB, the parents referred a 6-month history of dysphagia (Table 3).

\section{DISCUSSION}

The removal of a FB is a common procedure at tertiary referral children's hospitals and, over

TABLE 3. General characteristics of foreign bodies

\begin{tabular}{lcc}
\hline Type of foreign body & $\mathbf{n}$ & $\mathbf{( \% )}$ \\
Coins & 2045 & $(77.6)$ \\
Pin/needle/safety pin & 79 & $(3.0)$ \\
Jewelry & 78 & $(3.0)$ \\
Fish bones & 75 & $(2.8)$ \\
Plastic/toy & 71 & $(2.7)$ \\
Batteries & 48 & $(1.8)$ \\
Food & 43 & $(1.6)$ \\
Seeds & 35 & $(1.3)$ \\
Buttons & 28 & $(1.1)$ \\
Glass & 23 & $(0.9)$ \\
Others & 112 & $(4.2)$ \\
Removal method & & \\
Rigid endoscopy & 2259 & $(85.7)$ \\
Flexible endoscopy & 362 & $(13.7)$ \\
Pushed down & 9 & $(0.3)$ \\
Surgery & 7 & $(0.3)$ \\
Removal instrument & & \\
Alligator forceps & & \\
Dormia basket & 2298 & $(87.1)$ \\
Rat-tooth forceps & 158 & $(6.0)$ \\
Loop wire & 147 & $(5.6)$ \\
Pushed down & 18 & $(0.7)$ \\
Surgery & 9 & $(0.3)$ \\
\hline
\end{tabular}

45 years of experience at our facility, an average of 58.6 FB ingestions were observed per year and 4.88 FBs were removed per month, which is more than what was observed by Cheng, ${ }^{8}$ where 552 FBs were removed over 33 years and 5 months (17.2 per year and 1.4 per month), or almost equal to what was described by Russell, ${ }^{9}$ where 657 FBs were removed over 13 years, with an average of 50 per year and 4.1 per month. The male: female ratio was similar, unlike the reports by Little ${ }^{10}$ and Cheng, ${ }^{8}$ who found a male prevalence. Several articles have indicated that $75 \%$ of these accidents occur in children younger than 5 years, with a peak incidence between 6 months and 3 years old, similar to what has been observed in our series.,11 In this study, a little more than half of patients attended the Emergency Department in the first 24 hours after the ingestion, which is an average value between the reports indicating that $50 \%^{12}$ and $100 \%{ }^{11}$ of patients attended the Emergency Department in the first 36 hours. One third of subjects did not have symptoms at the time of the case history, but symptoms may occur in up to half of cases. ${ }^{17,18} \mathrm{To}$ confirm the diagnosis and locate the $\mathrm{FB}$, a frontal and lateral X-ray is necessary, including the neck, chest, and abdomen. ${ }^{7}$ In this study, a radiopaque FB was identified in most cases, similar to what was reported by Singh. ${ }^{19}$ Removal was performed, in all cases, under general anesthesia or sedation, as suggested by the North American Society for Pediatric Gastroenterology, Hepatology and Nutrition (NASPGHAN).22-22 The use of a rigid or flexible endoscope will depend on the FB type and location, and on the endoscopy team's experience. ${ }^{21}$ In our series, given the location of most FBs, removal was performed using a rigid endoscope. Among the patients who required a surgery, it is worth noting the case of a coin covered by the mucosa which could not be removed by endoscopy. A similar case was reported by Sink et al. ${ }^{12}$ in a child younger than 3 years with several unsuccessful attempts to remove the FB using a rigid esophagoscope, so removal was completed with an esophagostomy. Another stand-out case is that of a preschooler who swallowed 17 magnets that resulted in a gastrojejunal fistula. Tavarez et al. ${ }^{23}$ referred that if there are several magnets, they may stick together though the intestinal wall and exert enough pressure to cause tissue necrosis and form a fistula or perforation, as in this case. Eisenet al. ${ }^{21}$ recommend that the following instruments should be available for a successful removal: rat-tooth or alligator forceps, polypectomy loop, 
Dormia basket, wire net basket, and overtube. All these items are available nowadays.

The most commonly ingested FB were coins $^{9,12,15,18}$ because they are easily accessible; most were located in the upper third of the esophagus, similar to what was documented by other authors. ${ }^{24,25}$ Waltzman ${ }^{24}$ referred a $14 \%$ chance that a coin may pass spontaneously to the stomach if located in the upper third of the esophagus; a $43 \%$ chance if located in the middle third; and a $67 \%$ chance if located in the lower third; therefore, he suggested asymptomatic patients should remain under observation for 8-16 hours. If FBs are located in the stomach and cause obstruction symptoms, they should be removed once fasting is completed; ${ }^{20,21,25}$ however, if patients have no symptoms, health care providers may wait 4-6 weeks. ${ }^{20,21}$ In our case, we waited only 7-10 days, ${ }^{26}$ but other health care providers remove them at the time of diagnosis. ${ }^{27}$

Batteries are the second most commonly ingested blunt objects; the number of ingestions has increased in this decade. In an initial description, 10 batteries had been removed between 1996 and 2004; $;^{28}$ 21, between 1996 and 2007;,29 and 27 more, since that moment. A timely diagnosis and a rapid removal are critical to prevent complications that are common when the battery is $\geq 20 \mathrm{~mm}$ and contains lithium, because it has a voltage of 3 volts and has consequences 2-2.5 hours after ingestion, which may go from a burn wound followed by stenosis, a perforation with tracheoesophageal fistulas, mediastinitis, and fistulae to great vessels with massive bleeding, and death. ${ }^{30,31}$ The latest guidelines issued by the NASPGHAN and the European Society of Gastrointestinal Endoscopy (ESGE) recommend FB removal within 2 hours (as an emergency) if it is in the esophagus and within 48 hours if it is in the stomach and patients have no symptoms. ${ }^{32}$

FB impaction is most common in patients with an alteration of the esophagus; ${ }^{1,14,20,33}$ the guidelines recommend urgent removal in the case of complete obstruction and potential bronchial aspiration, and within 24 hours if there is partial obstruction and few symptoms..$^{20,32}$

Complications were uncommon and, in the case of severe complications, they have been described in several studies and related to FB type and location and a longer time elapsed since ingestion. 12,13,15,22,34

On the one side, the limitations of this study were the retrospective nature of data collection during the first phase, which may have resulted in biases, and the elimination of several medical records due to missing data. On the other side, the results of this study were comparable to those reported in other studies, and the description of such large number of pediatric patients with FB ingestion was very valuable from a medical stance.

\section{CONCLUSIONS}

FB ingestion is a very common accident in our setting, predominately among children younger than 5 years; FBs were most frequently located in the esophagus. The most common material was metal and, among metallic FBs, the most frequent were coins; however, disc batteries may cause severe complications, so it is important to diagnose their ingestion and remove them as soon as possible. A plain anterior-posterior and lateral $\mathrm{X}$-ray is the essential diagnostic test because most FBs are radiopaque; removal may be performed with a rigid or flexible endoscope, depending on the endoscopist's experience.

\section{REFERENCES}

1. KurowskiJA, Kay M. Causticingestions and foreign bodies ingestions in pediatric patients. Pediatr Clin North Am 2017; 64(3):507-24.

2. Green S. Ingested and aspirated foreign bodies. Pediatr Rev 2015; 36(10):430-6.

3. Chung S, Forte V, Campisi P. A review of pediatric foreign body ingestion and management. Clin Pediatr Emerg Med 2010; 11(3):225-30.

4. Coppola CP. Foreign body ingestion and aspiration. In: Coppola C, Kenedy A Jr, Scorpio R. Pediatrics Surgery: diagnosis and treatment. Cham: Springer; 2014.p.221-7.

5. Göktas Ö, SnideroS, Jahnke V, et al Foreign body aspiration in children: Field report of a German hospital. PediatrInt 2010; 52(1):100-3.

6. Kaushal P, Brown DJ, Lander L, et al. Aspirated foreign bodies in pediatric patients, 1968-2010: A comparison between the United States and other countries. Int J Pediatr Otorhinolaryngol 2011; 75(10):1322-6.

7. PugmireBS, Lim R, Avery L. Review of ingested and aspirated foreign bodies in children and the clinical significance for radiologists. Radiographics 2015; 355:1528-38.

8. Cheng $W$, Tam P. Foreign body ingestion in children: experience with 1265 cases. J Pediatr Surg 1999;34(10):1472-6.

9. Russell R, Lucas A, Johnson J, et al. Extraction of esophageal foreign bodies in children: rigid versus flexible endoscopy. Pediatr SurgInt 2014; 30(4):412-22.

10. Little DC, Shah SR, St Peter SD, et al. Esophageal foreign bodies in the pediatric population: our first 500 cases. $J$ Pediatr Surg 2006; 41(5):914-8.

11. Arana A, Hauser B, Hachimi-Idrissi S, et al. Management of ingested foreign bodies in childhood and review of the literature. Eur J Pediatr 2001; 160(8):468-72.

12. Sink JR, Kitsko DJ, Mehta DK, et al. Diagnosis of pediatric foreign body ingestion: clinical presentation, physical examination, and radiologic finding. An Otol Rhinol Laryngol 2016; 125(4):342-50.

13. Jayachandra S, Eslick G. A systematic review of paediatric foreign body ingestion: presentation, complications, and management. Int J Pediatr Otorhinolaryngol 2013;77(3):311-7. 
14. Cerri RW, Liacouras C. Evaluation and Management of foreign bodies in the upper gastrointestinal tract. Pediatr Case Rev 2003; 3(3):150-6.

15. Wright CC, ClossonF. Updates in pediatric gastrointestinal foreign bodies. Pediatr Clin North Am 2013; 60(5):1221-39.

16. Louie MC, Bradin S. Foreign body ingestion and aspiration. Pediatr Rev 2009; 30(8):295-301.

17. Uyemura MC. Foreign body ingestion in children. Am Fam Physician 2005; 72(2):287-91.

18. Chang YJ. Foreign body ingestion in children. An Emerg Med 2008; 51(4):484.

19. Singh A, Bajpai M, Panda SS, et al. Oesophagus foreign body in children: 15 years experience in a tertiary care paediatric center. Afr J Paediatr Sur 2014; 11(3):238-41.

20. Kramer RE, Lerner DG, Lin T, et al. Management of ingested foreign bodies in children: a clinical report of the NASPGHAN Endoscopy Committee.J Pediatr Gastroenterol Nutr 2015; 60(4):562-74.

21. Eisen GM, Baron TH, Dominitz JA, et al. Guideline for the management of ingested foreign bodies. Gastrointest Endosc 2002; 55(7):802-6.

22. Tokar B, Cevik AA, Ilhan H. Ingested gastrointestinal foreign bodies: predisposing factors for complications in children having surgical or endoscopic removal. Pediatr SurgInt 2007; 23(2):135-9.

23. Tavarez MM, Saladino RA, Gaines BA, et al. Prevalence, clinical features and management of pediatric magnetic foreign body ingestions. J Emerg Med 2013; 44(1):261-8.

24. Waltzman ML. Management of esophageal coins. Curr Opin Pediatr 2006; 18(5):571-4.

25. Wahbeh G, Wyllie R, Kay M. Foreign body ingestion in infants and children. Clin Pediatr (Phila) 2002; 41(9):633-40.
26. Blanco Rodríguez G, Velasco Soria L, PenchynaGrub J, et al. Cuerpos extraños subdiafragmáticos que requirieron manejo endoscópico o quirúrgico. Bol Med Hosp Infant Mex 2002; 59(11):700-5.

27. Kim JK, Kim SS, Kim JI, et al. Management of foreign bodies in the gastrointestinal tract: an analysis of 104 cases in children. Endoscopy 1999; 31(4):302-4.

28. Blanco Rodríguez G, Trauernicht Mendieta S, Pechyna Grub J, et al. Diagnóstico y tratamiento de pilas de disco o botón alojadas en el esófago del niño. Endoscopia 2006; 18(2): 149-53.

29. Blanco Rodríguez G, PenchynaGrub J, Ochoa Guajardo PL, et al. ¿Que tan urgente es extraer una pila de disco alojada en el esófago? Bol Med Hosp Infant Mex 2008; 65(4):282-9.

30. Litovitz T, Whitaker N, Clark L, et al. Emerging BatteryIngestion Hazard: Clinical implications. Pediatrics 2010; 125(6):1168-77.

31. Chang YJ, Chao HC, Kong MS, et al. Clinical analysis of disc battery ingestion in children. Chang Gung Med J 2004; 27(9):673-7.

32. Tringali A, Thomson M, Dumonceau JM, et al. Pediatric gastrointestinal endoscopy: European Society of Gastrointestinal Endoscopy (ESGE) and European Society for Paediatric Gastroenterology Hepatology and Nutrition (ESPGHAN) Guideline Executive summary. Endoscopy 2017; 49(1):83-91.

33. Diniz LO, Towbin A. Causes of esophageal food bolus impaction in the pediatric population. Dig Dis Sci 2012; 57(3):690-3.

34. Kimball SJ, Park AH, Rollins MD 2nd, et al. A review of esophageal disc battery ingestions and a protocol for management. Arch Otolaryngol Head Neck Surg 2010; 136(9):866-71. 